\title{
Neutrophil Adherence to Isolated Adult Cardiac Myocytes Induction by Cardiac Lymph Collected during Ischemia and Reperfusion
}

Keith Youker, ${ }^{*}$ C. Wayne Smith, ${ }^{\ddagger}$ Donald C. Anderson, ${ }^{\ddagger}$ ll David Miller,* Lloyd H. Michael," Roger D. Rossen," and Mark L. Entman*

${ }^{*}$ Section of Cardiovascular Sciences, Department of Medicine, The Methodist Hospital and The DeBakey Heart Center; ${ }^{\ddagger}$ Speros P. Martel Laboratory of Leukocyte Biology, Department of Pediatrics, Texas Children's Hospital; Departments of ${ }^{\S}$ Cell Biology, and

"Microbiology and Immunology, "Veterans Administration Hospital, Baylor College of Medicine, Houston, Texas 77030

\section{Abstract}

Canine neutrophils can be induced to adhere in vitro to isolated adult cardiac myocytes by stimulation of the neutrophils with chemotactic factors such as zymosan-activated serum (ZAS) only if the myocytes have been previously exposed to cytokines such as interleukin 1 (IL-1) or tumor necrosis factor- $\alpha$. These cytokines induce synthesis and surface expression of intercellular adhesion molecule-1 (ICAM-1) on the myocyte, and neutrophil adhesion is almost entirely CD18 and ICAM-1 dependent. The present study examines cardiac-specific lymph collected from awake dogs during 1-h coronary occlusion and $3 \mathrm{~d}$ of reperfusion for its ability to induce both ICAM-1 expression in cardiac myocytes, and neutrophil-myocyte adherence. Reperfusion lymph induced ICAM-1 expression in isolated myocytes, and myocyte adherence to ZAS-stimulated neutrophils that was completely inhibited by anti-CD18 and anti-ICAM-1 monoclonal antibodies. This activity peaked at $90 \mathrm{~min}$ of reperfusion and persisted for up to $72 \mathrm{~h}$. Preischemic lymph was not stimulatory. IL-1 appeared not to be a stimulating factor in lymph in that dilutions of lymph were found to inhibit the stimulatory effects of recombinant IL-1 $\beta$. However, investigation of interleukin 6 (IL-6) revealed that recombinant IL-6 stimulated myocyte adhesiveness for ZAS-stimulated neutrophils (ED so $=0.002 \mathrm{U} / \mathrm{ml}$ ) and expression of ICAM-1 by isolated myocytes. IL-6 neutralizing antibody markedly reduced the ability of reperfusion lymph to stimulate adhesion and ICAM-1 expression, and estimates of levels of IL-6 in reperfusion lymph ranged from 0.035 to $0.14 \mathrm{U} / \mathrm{ml}$. These results indicate that cytokines capable of promoting neutrophil-myocyte adhesion occur in extracellular fluid during reperfusion of ischemic myocardium, and that one of these cytokines is IL-6. Neutrophilmyocyte adhesion may be of pathogenic significance because it may enhance the cytotoxic activity of the neutrophil. ( $J$. Clin. Invest. 1992. 89:602-609.) Key words: cardiac lymph • cytokine induction • intercellular adhesion molecule-1 $\bullet$ interleukin 6 - ischemia-reperfusion injury

\section{Introduction}

Numerous studies indicate that neutrophils contribute to myocardial cell injury after ischemia particularly under conditions

Address reprint requests to Dr. Entman, Section of Cardiovascular Sciences, Department of Medicine, Baylor College of Medicine, One Baylor Plaza, Houston, TX 77030.

Received for publication 1 July 1991 and in revised form 25 September 1991

J. Clin. Invest.

(c) The American Society for Clinical Investigation, Inc.

$0021-9738 / 92 / 02 / 0602 / 08 \quad \$ 2.00$

Volume 89, February 1992, 602-609 where reperfusion of the ischemic area with normally oxygenated blood has occurred (1). In animal models involving removal of neutrophils from the circulation (2-4), there are generally measurable reductions in the extent of myocardial damage. The mechanism by which neutrophils extend the tissue injury associated with myocardial infarction has not been completely elucidated although there are two general categories of pathophysiologic mechanisms. (a) Activated neutrophils may change shape, become more rigid, and lodge in capillary and small vessels, thereby altering perfusion and damaging vessel integrity and function (5-7). (b) Neutrophils that adhere to the endothelium and migrate into the extravascular space secrete products (e.g., oxygen free radicals, proteases) that are directly cytotoxic (8).

We have previously described adherence of neutrophils to adult canine cardiac myocytes that required both cytokine stimulation of the myocyte and chemotactic stimulation of the neutrophil (9). Protein synthesis by the myocytes was necessary and neutrophil adhesion was inhibited by the anti-CD18 monoclonal antibody (MAb) R15.7. In a recent paper, Smith et al. (10) demonstrated that cytokines stimulate expression of intercellular adhesion molecule-1 (ICAM-1) ${ }^{1}$ in the myocyte and that adherence is blocked by the anti-ICAM-1 MAb CL18/6. Such adherence, if it occurs in ischemic and reperfused tissue, may be of pathologic significance because it would provide a close proximity for effective myocyte damage by neutrophil secretory products of limited half-life (e.g., oxygen radicals), and it may augment the $\mathrm{H}_{2} \mathrm{O}_{2}$ production by chemotactically stimulated neutrophils $(9,11,12)$. By using a model that allows sampling of cardiac specific lymph from awake unanesthetized animals during reperfusion after coronary occlusion, we have demonstrated in postischemic cardiac lymph $\mathrm{Clq}$ binding proteins of cardiac origin that initiate the classical complement pathway $(13,14)$, the presence of chemotactic activity, and activated neutrophils (15). If neutrophil adherence to cardiac myocytes occurs in vivo, we postulated that postischemic cardiac lymph would not only contain the ability to activate neutrophils, but would be capable of inducing adhesiveness in the myocyte. The present study describes the induction of CD18- and ICAM-1-dependent neutrophil-myocyte adherence by postischemic cardiac lymph. In addition, we provide evidence that the principle cytokine found in postischemic lymph responsible for stimulating the myocyte is interleukin 6 (IL-6).

\section{Methods}

Ischemic protocol. Healthy mongrel dogs (15-25 kg) of either sex were used in this study as previously described $(9,13-15)$. Each animal was

1. Abbreviations used in this paper: CJVEC, canine jugular vein endothelial cells; ICAM-1, intercellular adhesion molecule-1;PCR, polymerase chain reaction; TNF $\alpha$, tumor necrosis factor- $\alpha$; ZAS, zymosan-activated serum. 
anesthetized with sodium pentobarbital $(30 \mathrm{mg} / \mathrm{kg})$, intubated, and ventilated with room air by a respirator (Harvard Apparatus Co., Inc., S. Natick, MA). A midline thoracotomy provided access to the heart and mediastinum. Using techniques previously described, cannulation of the cardiac lymph duct was then performed (15). Briefly, injection of $0.05-0.2 \mathrm{ml}$ of $0.5 \%$ Evans blue subepicardially into the posterolateral wall of the left ventricle allowed lymphatic vessel definition. The largest vessel was selected and cannulated (PE 10-90) at a site proximal to the cardiac lymph node and $2-5 \mathrm{~cm}$ from the base of the heart. Accessory noncardiac lymphatic vessels and tracheobronchial lymphatic connections in this region were ligated. Subsequently, a hydraulically activated occluding device and a Doppler flow probe designed and fabricated by our laboratory (15) were secured around the circumflex coronary artery just proximal or just distal to the first distal branch. Choice of location depended on the proximity and anatomical arrangement of lymphatic vessels adjacent to the coronary vessels so that subsequent dissection would not damage the lymphatic system. To prevent damage of lymphatic vessels in close proximity to the coronary vasculature, dissection of adipose tissue adjacent to the coronary vessel at two sequential 3-4-mm sections was carefully performed with subsequent placement of the occluding device and flow probe. In animals selected for experimental assessments of cardiac lymph, intact lymphatic vessels draining the regions of ischemic myocardium were identified by injecting Evans blue $(0.05 \mathrm{ml})$ into the free wall of the left ventricle after the occluder and flow probe were in place. The appearance of Evans blue in the cardiac lymph cannula confirmed the patency of the lymph vessel architecture. Cannulas were also placed in the right and left atria to allow for blood sampling as needed.

The animal was allowed to recover for at least $72 \mathrm{~h}$ before occlusion. The protocol used in these studies involved a 1-h occlusion of the left circumflex coronary artery followed by reperfusion for up to $72 \mathrm{~h}$. During occlusion and reperfusion, ischemia was verified by the Doppler probe and characteristic electrocardiograph changes detected with standard limb lead electrodes. Blood flow in the circumflex was continuously monitored with flow probes to assure occlusion and reperfusion. Lymph samples $(1 \mathrm{ml})$ were collected from the cannula tubing in tubes containing $10 \mathrm{U}$ of heparin. The samples were spun in a table-top centrifuge at $13,000 \mathrm{~g}$ for $5 \mathrm{~min}$. The supernatant was taken, aliquoted, frozen in liquid nitrogen, and stored at $-70^{\circ} \mathrm{C}$ until use. Once thawed, lymph samples were used immediately and never refrozen or stored thawed.

Isolation of cardiac myocytes. Previously described procedures were used (9). Briefly, healthy mongrel dogs weighing $10-15 \mathrm{~kg}$ were anesthetized using sodium pentobarbital. The heart was removed through the left lateral chest under sterile conditions, and immediately placed in ice-cold saline. The aorta was then cannulated using a tubing adapter suitable for the individual heart. The adapter was then connected to a peristaltic pump and retrograde perfusion was initiated at 50-60 $\mathrm{ml} / \mathrm{min}$ using medium A (Joklik modified minimum essential medium [Sigma Chemical Co., St. Louis, MO], containing 2 g/liter sodium bicarbonate, $0.1 \%$ fatty acid-free bovine serum albumin and equilibrated with $95 \% \mathrm{O}_{2} / 5 \% \mathrm{CO}_{2}$ before perfusion); perfusion was maintained several minutes until all left ventricle vessels were cleared of blood. The perfusate was then changed to medium B (medium A containing $120 \mathrm{U} / \mathrm{ml}$ collagenase type III [Worthington Biochemical Corp., Freehold, NJ]) and perfusion continued for $10 \mathrm{~min}$. At this point the heart was removed from the cannulas and $10 \mathrm{~g}$ of left ventricle were trimmed of connective tissue then minced and placed in an Erlenmeyer flask containing $50 \mathrm{ml}$ medium B. The flask was equilibrated with $95 \% \mathrm{O}_{2} / 5 \% \mathrm{CO}_{2}$ gas, sealed, and placed in a shaker bath at $90-100 \mathrm{cycles} / \mathrm{min}$ at $35^{\circ} \mathrm{C}$. After $20 \mathrm{~min}$ the supernatant was filtered through one layer of cheesecloth and another $50 \mathrm{ml}$ of medium B added and the procedure repeated five to six times. These cells were allowed to settle at room temperature for $\sim 5 \mathrm{~min}$ and the overlying solution was removed. The cell pellet was then suspended in medium $A$ and the cells allowed to settle. This wash was then repeated and viability was measured using trypan blue dye exclusion. Preparations with a viability of $>80 \%$ were used in incubation experiments with neutrophils. Cells were then placed on ice and used within 1-2 d. Viability and adhesion following stimulation were not appreciably altered over this period.

Neutrophil isolation. Canine neutrophils were isolated from citrate anticoagulated venous blood using techniques previously described for the isolation of human neutrophils (16). This yielded a preparation of cells $>95 \%$ neutrophils with $>99 \%$ viability. These cells were suspended in Dulbecco's phosphate-buffered balanced salt solution (PBS) and stored at $4^{\circ} \mathrm{C}$ for up to $4 \mathrm{~h}$.

MAbs. The anti-CD18 MAb R15.7 (IgG1) (9) was supplied by Dr. Robert Rothlein (Boehringer Ingleheim Pharmaceuticals, Inc., Ridgefield, CT). The anti-canine ICAM-1 MAbs CL18/6 (IgG1) and CL16/ $1 \mathrm{D} 8$ (IgG1) were prepared as described elsewhere (10) and used as in the present study as a $\mathrm{F}\left(\mathrm{ab}^{\prime}\right)_{2}$ fragments. A binding control antibody, SG10G8 (IgG1) recognizing an undefined epitope on the canine neutrophil, was prepared and used as previously described (10). This MAb binds to canine neutrophils at about the same level as R15.7, and has not been found to inhibit adhesion of canine neutrophils under any conditions tested. A second binding control for neutrophils was used, MAb LM2/1 (IgG1) (17). We have previously shown that this MAb binds to canine neutrophils but fails to block any adhesive functions tested (12).

Canine neutrophil adherence to canine endothelial monolayers. Canine jugular vein endothelial cells (CJVEC) were obtained by a modifcation of the method of Ford (18) as previously described (10). Jugular veins were everted on glass rods and incubated in collagenase solution (Worthington Biochemical Corp., type III, $50 \mathrm{U} / \mathrm{ml}$ ) for $10 \mathrm{~min}$. Cells were collected by centrifugation and suspended in Dulbecco's modified Eagle's medium (DME) containing 4\% fetal calf serum, $4 \%$ bovine calf serum, $50 \mu \mathrm{g} / \mathrm{ml}$ endothelial cell growth factor (ECGF, Collaborative Research, Inc., Waltham, MA), $50 \mu \mathrm{g} / \mathrm{ml}$ heparin, $1 \mathrm{mM}$ sodium pyruvate, and antibiotics. Cells were seeded in Primaria flasks (Becton, Dickinson \& Co., Lincoln Park, NJ). After $2-4 \mathrm{~d}$ of incubation at $37^{\circ} \mathrm{C}$ in $\mathrm{C} \mathrm{CO}_{2}$ incubator, areas of cells with "cobble-stone" morphology were collected by scraping, transferred to gelatin-coated flasks and grown to confluence. Second-passage cells were obtained by scraping, seeded onto type I collagen-coated $(5 \mu \mathrm{g} / \mathrm{ml}) 25-\mathrm{mm}$ round cover glasses, and grown to confluence. Only preparations of cells where representative uniform monolayers exhibited acetylated-low density lipoprotein (Dilac-LDL, Biomedical Technologies, Inc., Stoughton, MA) uptake and endothelial ("cobble-stone") morphology were used in adhesion assays. Coverslips with attached CJVEC monolayers were inserted into adhesion chambers, and adherence of isolated canine neutrophils was determined in the absence of shear stress using a visual assay as previously described $(10,16,18,19)$. In experiments using inhibitory MAbs, neutrophils were incubated with MAb at room temperature for $5 \mathrm{~min}$ before cell suspensions containing the MAb were injected into the adherence chambers.

Canine neutrophil-myocyte adherence. Isolated canine myocytes were suspended in medium $A$ at a concentration of $50,000 / \mathrm{ml}$ as previously described (9). Neutrophils and myocytes were coincubated in a volume of $0.4 \mathrm{ml}$ at a neutrophil/myocyte ratio of $10: 1$, for $60 \mathrm{~min}$ at $37^{\circ} \mathrm{C}$. The cells were resuspended and small aliquots transferred to a microscope slide for examination under phase contrast or differential interference contrast optics. For each preparation, the number of neutrophils adherent to each of 200 myocytes was counted. Samples were coded so that data collection was performed without knowledge of the specific experimental conditions. Myocytes were incubated in the presence or absence of cytokines including human recombinant IL- $1 \beta$ (Genzyme Corp., Boston, MA), human recombinant IL-6 (Genzyme Corp.), human recombinant tumor necrosis factor- $\alpha$ (TNF $\alpha$ ) (Boehringer-Ingelheim Pharmaceuticals, Inc.), or cardiac lymph, for various times at $37^{\circ} \mathrm{C}$ before addition of the neutrophils. Polyclonal neutralizing antibodies to IL-6 were obtained from Genzyme Corp. In experiments with stimulated neutrophils, zymosan-activated serum (ZAS, prepared as previously described (15) was added immediately before the neutrophil suspension was mixed with the suspension of myocytes. In some studies, the R15.7 MAb, previously shown in the canine system to be inhibitory for CD18, was added to the neutrophil- 
myocyte suspension (final concentration of $10 \mu \mathrm{g} / \mathrm{ml}$ ) and was present throughout the incubation period.

Evaluation of the effects of protein synthesis inhibitors on the cytokine-induced myocyte-neutrophil adhesion was carried out in the following way. Myocytes were incubated for $3 \mathrm{~h}$ at $37^{\circ} \mathrm{C}$ in the presence of recombinant $(\mathrm{r}) \mathrm{IL}-6(2 \mathrm{U} / \mathrm{ml})$ with or without actinomycin D $(5 \mu \mathrm{g} /$ $\mathrm{ml}$ ) or cycloheximide $(5 \mu \mathrm{g} / \mathrm{ml})$ (both from Sigma Chemical Co.). Adhesion was assessed as described above.

Northern blot analysis of canine ICAM-1 mRNA. A partial canine ICAM-1 cDNA was prepared by homology cloning as previously described in detail (10). Briefly, degenerate oligonucleotide primer mixtures were selected to correspond to highly conserved sequences of murine and human ICAM-1 cDNA within Ig domains 2 and 5. Using these primer mixtures, canine spleen CDNA was amplified using the polymerase chain reaction (PCR) (20). PCR reactions were analyzed on $1 \%$ agarose gels followed by Southern blotting (21) and hybridized with labeled human or murine cDNA probes for ICAM-1 (22). A product of $740 \mathrm{bp}$ was observed by ethidium staining and in hybridization protocols. The canine PCR product was cloned into M13mp18 (23) and sequenced using the dideoxy chain termination method (24). Sequence analyses revealed nucleotide identity of $53.8 \%$ between canine and human and $61.2 \%$ between canine and murine. The nucleotide sequence of this partial cDNA is available in Genbank (accession number M68524).

RNA was isolated from CJVEC or canine myocytes using the acidguanidinium-phenol chloroform procedure (25). RNA (10-20 $\mu \mathrm{g})$ was electrophoresed on $1 \%$ agarose gels containing $1 \%$ formaldehyde and then transferred to a nitran membrane (Gene Screen Plus, New England Nuclear, Boston, MA) by standard procedures (21). The membranes were hybridized in 50\% formamide, $10 \%$ dextran sulfate, $1 \%$ SDS, $96 \mathrm{mM} \mathrm{NaCl}, 0.15 \mathrm{mg} / \mathrm{ml}$ salmon sperm DNA, and $4 \times 10^{6} \mathrm{cpm}$ of random hexamer-labeled canine probe. Filters were washed with $2 \times$ SSC at $21^{\circ} \mathrm{C}$ for $5 \mathrm{~min}$ twice and with $2 \times \mathrm{SSC}$ with $1 \% \mathrm{SDS}$ at $65^{\circ} \mathrm{C}$ for 30 min twice and were then exposed to XLR film (Eastman Kodak Co., Rochester, NY).

Data presentation. Results are presented as mean numbers of neutrophils bound per myocyte \pm standard error, each experiment was repeated at least five times. Statistical assessments were made using Student's $t$ test or analysis of variance and Dunnett's $t$ test.

\section{Results}

Postischemic cardiac lymph stimulates adhesiveness of cardiac myocyte for canine neutrophils. Cardiac lymph samples taken before occlusion of the coronary artery had no significant effect on neutrophil-myocyte adherence (Fig. 1). However, significant increases in neutrophil-myocyte adherence were observed when myocytes were incubated with lymph collected during the first hour of reperfusion. Significant stimulatory activity peaked at $90 \mathrm{~min}$ of reperfusion and persisted up to $72 \mathrm{~h}$ (Fig. 2). The monoclonal antibody R15.7 (anti-CD18) completely inhibited the neutrophil adherence induced at the peak stimulatory times (Fig. 2) and at later times tested throughout the 24-h reperfusion period (data not shown). The binding control antibody LM2/1 did not inhibit adhesion (data not shown). Addition of actinomycin D $(5 \mu \mathrm{g} / \mathrm{ml})$ or cycloheximide $(5 \mu \mathrm{g} / \mathrm{ml})$ inhibited by $>85 \%$ the adherence induced by the $90-\mathrm{min}$ reperfusion lymph samples (Fig. 2, bottom).

Postischemic cardiac lymph was also evaluated for its ability to enhance the adhesiveness of CJVEC monolayers for neutrophils (Fig. 3). After a 3-h incubation of endothelial monolayers with a 1:7 dilution of the lymph, the adhesion of unstimulated neutrophils was significantly enhanced. This effect was most evident when lymph collected 60-90 min after of reperfusion was used, and stimulatory activity could be de-

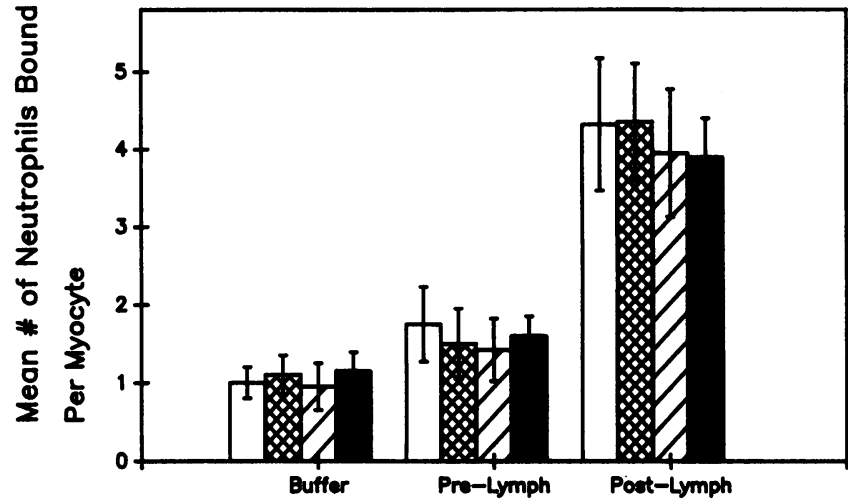

Figure 1. Adherence of neutrophils to cardiac myocytes preincubated in cardiac lymph. Isolated canine cardiac myocytes were incubated at $37^{\circ} \mathrm{C}$ in PBS or in various dilutions of cardiac lymph for $3 \mathrm{~h}$. Neutrophils (10:1 ratio with myocytes) and ZAS (1\%) were added during the fourth hour of incubation, and then aliquots were visually evaluated for the level of neutrophil-myocyte adhesion. Lymph dilu-

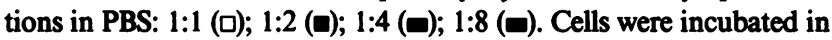
PBS alone (Buffer), dilutions of cardiac lymph collected prior to occlusion of the coronary artery (Pre-Lymph), or in dilutions of cardiac lymph collected $90 \mathrm{~min}$ after coronary reperfusion was begun (PostLymph). The ischemic period was 1 hour before reperfusion.

tected for up to $24 \mathrm{~h}$. As was also observed with myocytes, this increased adhesion was almost totally inhibited by the antiCD18 MAb R15.7 and by the anti-ICAM-1 MAb, CL18/6, but was not inhibited (data not shown) by MAbs SG10G8 or CL18/1D8 (an anti-ICAM-1 antibody previously shown to bind to a nonfunctional epitope on canine ICAM-1 [10]).

In the previous experiments, incubations proceeded for $3 \mathrm{~h}$ after which neutrophil adherence to myocytes was assessed during the fourth hour. In an attempt to evaluate the time dependence of this process, myocytes were incubated with postischemic cardiac lymph (90-min sample) for various lengths of time after which the cells were washed and then incubated in PBS alone (as shown in Fig. 4). A time-dependent increase in neutrophil-myocyte adherence was seen for up to $8 \mathrm{~h}$. After $8 \mathrm{~h}$ (data not shown), the results became unreliable because of a decreased viability of myocytes incubated for this interval. Neutrophil adherence after continuous exposure of myocytes to the lymph sample for $4 \mathrm{~h}$ was not greater than that seen for washed myocytes incubated for $4 \mathrm{~h}$ after a 30 -min exposure to lymph. Thus, a relatively short exposure of myocytes to extracellular fluid collected from ischemic myocardium results in a delayed and progressive increase in their potential to bind neutrophils.

The ability of postischemic cardiac lymph to stimulate myocyte adhesiveness is inhibited by anti-IL-6. An initial hypothesis was that cytokines found in postischemic cardiac lymph are responsible for the induction of neutrophil adhesion molecules on the cardiac myocytes in that we have found previously that rIL- $1 \beta$, for example, is capable of inducing increased adhesiveness for neutrophils (9) and the expression of ICAM-1 on the myocyte (10). The effect of rIL- $1 \beta$ is confirmed by data in Fig. 5 . Incubation of cardiac myocytes with human rIL-1 $\beta$ enhanced adhesion for neutrophils in a dose-dependent manner. However, a 1:10 dilution of preischemic cardiac lymph, which does not stimulate myocytes, inhibited the effects of rIL- $1 \beta$ over this entire concentration range. Thus it appears unlikely that $\mathrm{IL}-1$ is responsible for stimulation of myocyte adherence 

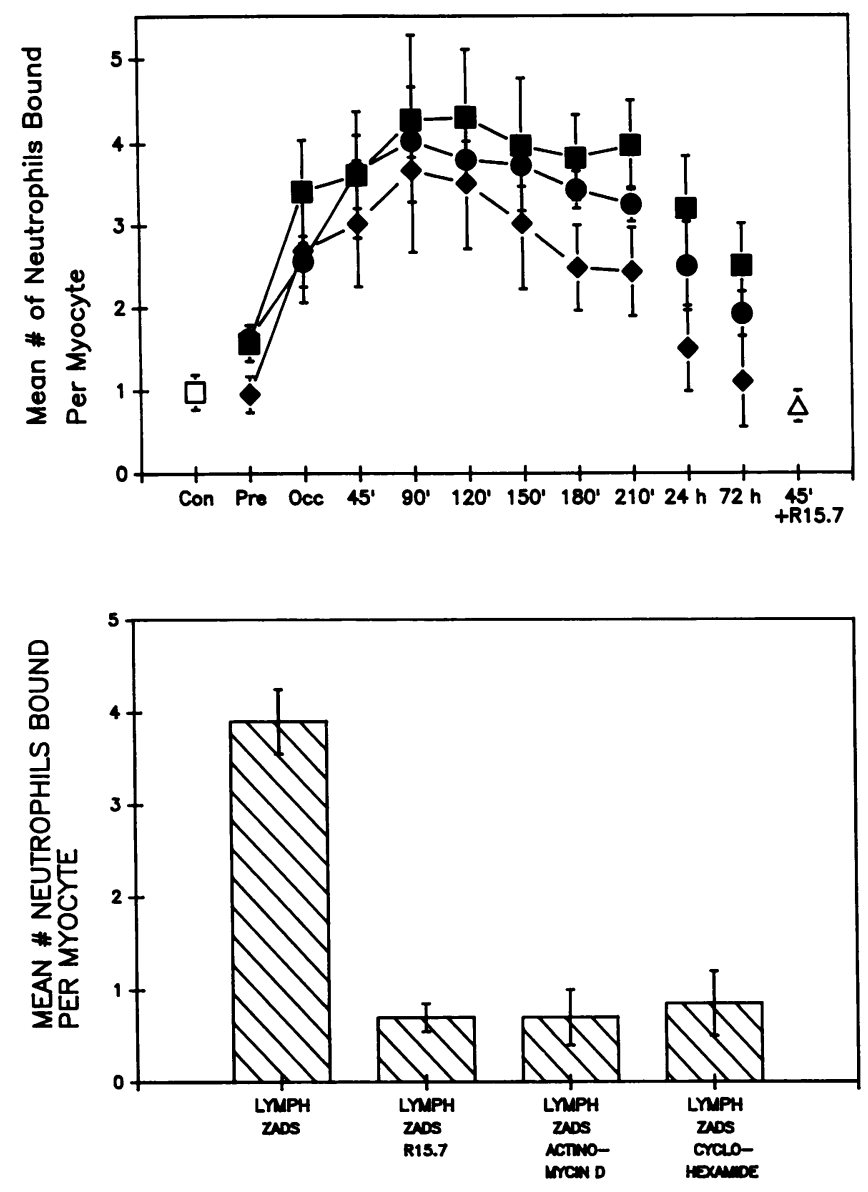

Figure 2. Stimulation of neutrophil-cardiac myocyte adherence by lymph from ischemic and reperfused myocardium. Isolated canine cardiac myocytes were incubated at $37^{\circ} \mathrm{C}$ in PBS or in various dilutions of cardiac lymph for $3 \mathrm{~h}$. Neutrophils (10:1 ratio with myocytes) and ZAS (1\%) were added during the fourth hour of incubation, and then aliquots were visually evaluated for the level of neutrophil-myocyte adhesion. Top: Lymph dilutions in PBS: 1:7 (a); 1:10 (๑); 1:20

(४). Cells were incubated in PBS alone (Con, 口), dilutions of cardiac lymph collected before occlusion of the coronary artery (Pre), dilutions of cardiac lymph collected during the 1-h period of occlusion $(O c c)$, or dilutions of cardiac lymph collected at the indicated times after coronary reperfusion was begun. The level of adhesion after addition of anti-CD18 MAb R15.7 $(10 \mu \mathrm{g} / \mathrm{ml})$ to cells incubated with a 45-min reperfusion lymph sample and ZAS as described above is also shown $(\Delta)$. Bottom: Lymph collected at $45 \mathrm{~min}$ of reperfusion was used to assess the need for protein synthesis in the up-regulation of myocyte adhesiveness. Myocytes were exposed to this lymph as described above in the presence of $5 \mu \mathrm{g} / \mathrm{ml}$ of the indicated protein synthesis inhibitors. The resulting levels of adhesion of ZAS-stimulated neutrophils were significantly $(P<0.01, n=3)$ reduced compared with adherence in the absence of these inhibitors.

in vivo. These data suggest the presence of an inhibitor of IL-1 action (e.g., an IL-1 receptor antagonist [26-28]) in cardiac lymph.

As a result of surveying different cytokines for the ability to stimulate the adhesiveness of cardiac myocytes, we found that recombinant human IL-6 was active. As shown in Fig. 6, myocytes responded to concentrations of rIL-6 as low as $0.001 \mathrm{U} /$ $\mathrm{ml}$; CJVEC showed no response upon incubation with a wide range of concentrations of rIL-6 $(0.03-30 \mathrm{U} / \mathrm{ml})$ (data not shown). This effect of human recombinant IL-6 on dog myo-

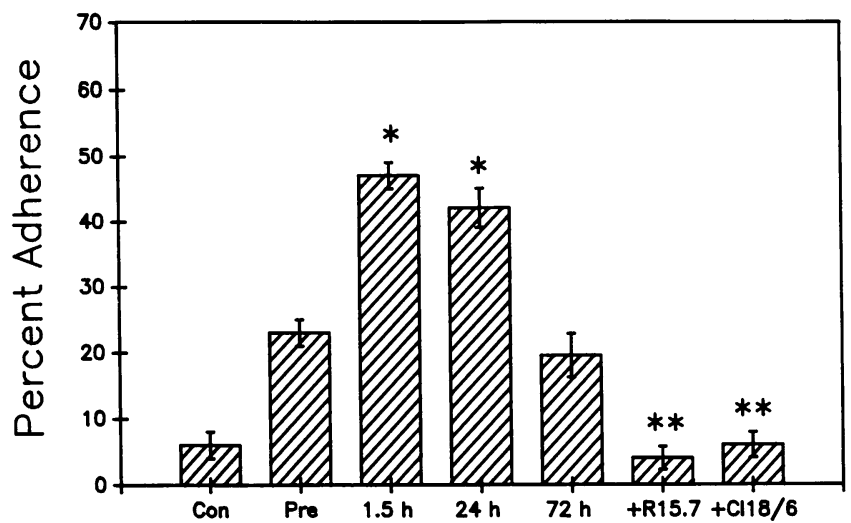

Figure 3. Effect of postischemic cardiac lymph on canine neutrophil-endothelial cell adhesion. Monolayers of CJVEC were exposed to a $1: 7$ dilution of cardiac lymph for $3 \mathrm{~h}$ at $37^{\circ} \mathrm{C}$, washed, and then placed in adhesion chambers. The adhesiveness for unstimulated isolated canine neutrophils was evaluated visually after a 500 -s contact time and a 500-s detachment time at unit gravity. CJVEC were incubated in culture media only (control), 1:7 dilution of lymph collected before ischemia (Pre), or 1:7 dilutions of lymph collected 1.5, 24, or $72 \mathrm{~h}$ after the onset of reperfusion. The effects of anti-CD18 MAb $\mathrm{R} 15.7(10 \mu \mathrm{g} / \mathrm{ml})$ or anti-ICAM-1 MAb CL18/6 on adhesion stimulated by the dilution of the 1.5 -h lymph sample is also shown.

cytes was inhibited by a polyclonal neutralizing antibody in a concentration-dependent manner (Fig. 7). As shown in Fig. 8, anti-IL-6 did not inhibit stimulation of adherence by optimal concentrations of other cytokines including rIL- $1 \beta$ and rTNF $\alpha$. The antibody to human IL-6 also inhibited the ability of cardiac lymph to enhance myocyte-neutrophil adherence (Fig. 9), but did not inhibit the increased adherence induced in CJVEC (data not shown). If one assumes that this antibody is as capable of blocking the effect of canine IL-6 in cardiac lymph as it is in blocking the effects of human recombinant IL-6 (as shown in Fig. 7), it can be estimated that IL-6 concentrations within the cardiac lymph after $90 \mathrm{~min}$ of reperfusion range from 0.035 to $0.14 \mathrm{U} / \mathrm{ml}$.

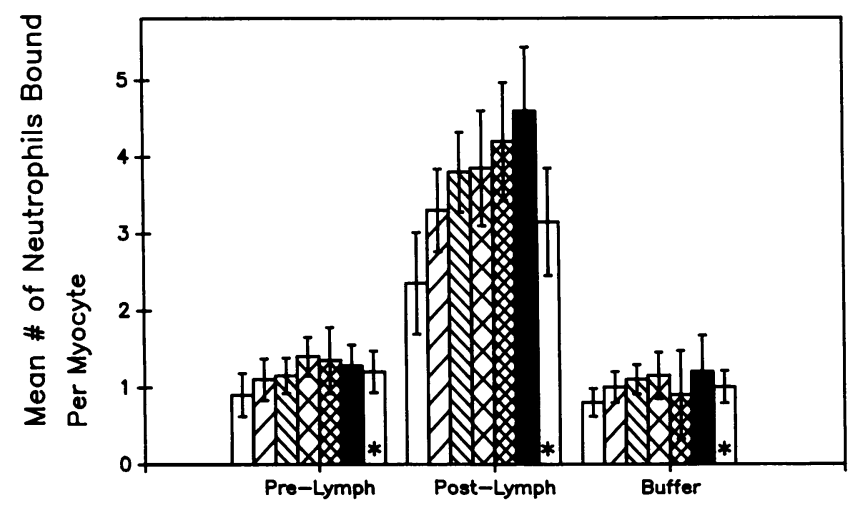

Figure 4. Stimulation of neutrophil-cardiac myocyte adherence by lymph from ischemic and reperfused myocardium. Isolated myocytes were exposed to preischemic lymph, postischemic lymph or buffer in a dilution of $1: 7$ for $30 \mathrm{~min}$ at $37^{\circ} \mathrm{C}$ and washed. Cells were resuspended in PBS and the incubation was continued for up to $8 \mathrm{~h}$ as

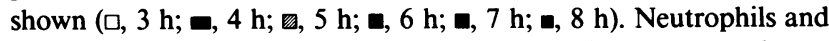
ZAS $(1 \%)$ were added in the final hour of incubation. The open bar with asterisk denotes adherence to myocytes which were incubated with cardiac lymph for $4 \mathrm{~h}$ with no washing. 


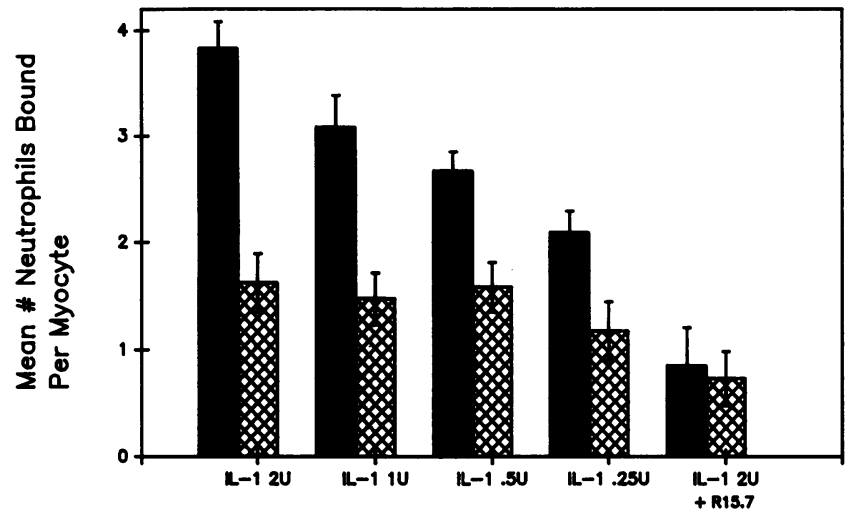

Figure 5. Stimulation of neutrophil-myocyte adhesion by rIL-1 $\beta$, effects of cardiac lymph. Isolated cardiac myocytes were incubated with varying concentrations of rIL- $1 \beta$ for $3 \mathrm{~h}$ at $37^{\circ} \mathrm{C}$ in the presence ( $\square$ ) or absence $(\square)$ of a 1:10 dilution of preischemic canine cardiac lymph. Neutrophils and ZAS (1\%) were added during the fourth hour, and adhesion was determined visually. The effect of adding anti-CD18 MAb R15.7 (10 $\mu \mathrm{g} / \mathrm{ml})$ are also shown.

The adherence receptor on cardiac myocytes induced by rIL-6 and cardiac lymph is ICAM-1. The finding that adhesion of neutrophils to stimulated myocytes is $\mathrm{CD} 18$ dependent suggested the possibility that IL-6 and reperfusion lymph induce the expression of ICAM-1, a known counter-receptor for CD18 heterodimers $(16,29)$. We have previously reported that canine myocytes demonstrate high levels of CD18-dependent adherence to chemotactically activated neutrophils when preincubated with rIL-1 $\beta$, rTNF $\alpha$, or endotoxin $(9,10)$. More recently we have demonstrated that this adherence is associated with increased levels of canine ICAM-1 mRNA and surface ICAM1 expression invoked by these stimuli (10). As shown in Fig. 10, rIL-6 and cardiac lymph also induced increased levels of ICAM-1 mRNA in isolated cardiac myocytes. Anti-IL-6 partially, but not totally, reduced the level of ICAM-1 mRNA elicited by reperfusion lymph (Fig. 10, right). In addition, the anti-canine ICAM-1 MAb CL18/6 almost completely inhibited neutrophil adhesion to myocytes induced by incubation in rIL-6, reperfusion lymph, or rIL-1 (Fig. 11).

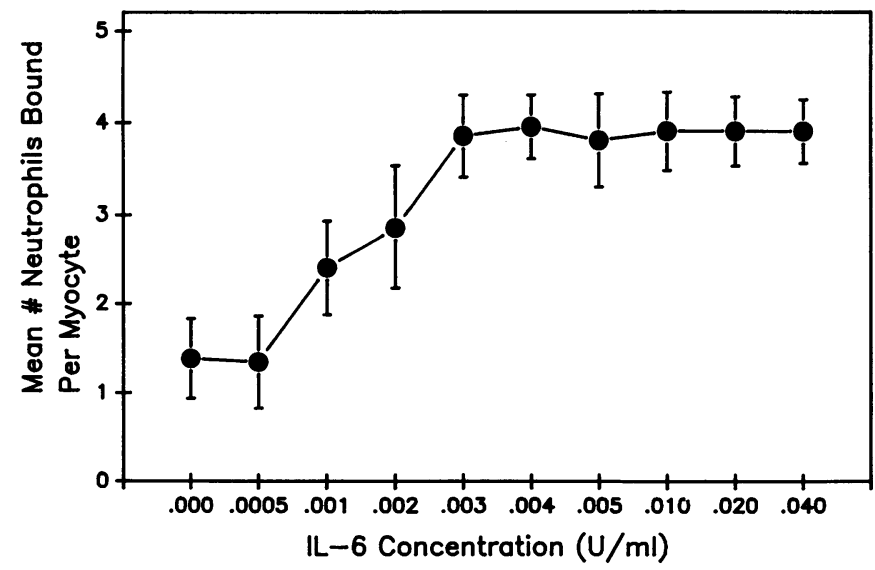

Figure 6. Stimulation of neutrophil-myocyte adhesion by rIL-6. Isolated cardiac myocytes were incubated with varying concentrations of rIL-6 for $3 \mathrm{~h}$ at $37^{\circ} \mathrm{C}$. Neutrophils and ZAS (1\%) were added during the fourth hour, and adhesion was determined visually.

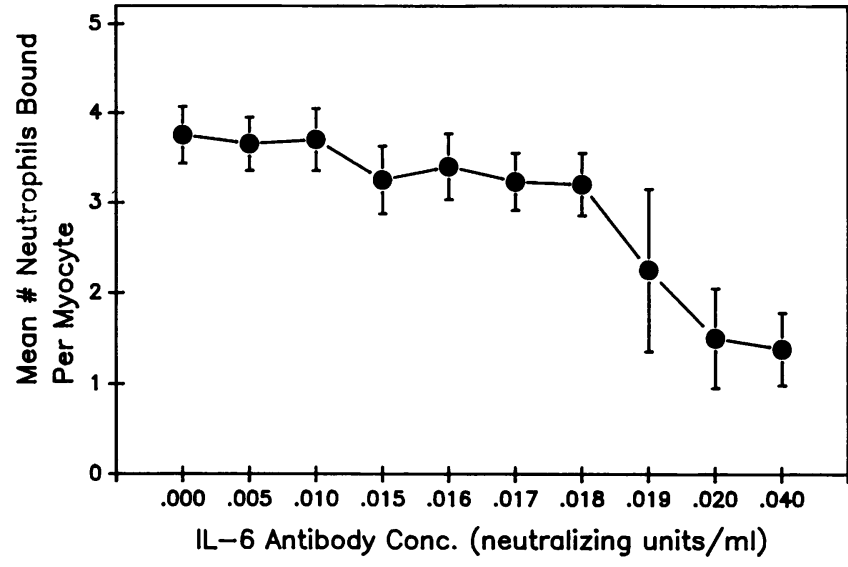

Figure 7. Effect of neutralizing antibody to human rIL-6 on neutrophil-myocyte adherence induced by rIL-6. Isolated canine cardiac myocytes were preincubated at $37^{\circ} \mathrm{C}$ for $3 \mathrm{~h}$ with rIL-6 $(0.020 \mathrm{U} / \mathrm{ml})$ and varying concentrations of anti-IL-6 polyclonal antibodies as shown. Neutrophils and ZAS (1\%) were added during the fourth hour, and adhesion was determined visually.

\section{Discussion}

There is strong clinical evidence that reperfusion by thrombolytic therapy is effective in salvaging ischemic myocardium for as long as $6 \mathrm{~h}$ after the onset of ischemia in humans. However, processes other than the ischemic insult may influence the degree of myocardial cell damage resulting from coronary occlusion. Considerable evidence has pointed to the role of an inflammatory reaction induced by the ischemic event which may be enhanced by reperfusion and extend the tissue injury (2-4, $30-35$ ). The primary evidence for a pathologenic role of inflammation comes from studies where neutrophils have been depleted utilizing anti-neutrophil antibodies $(2,3)$ or cell filters (36), or where neutrophil function is inhibited by drugs (37-39) or MAbs $(40,41)$. Such experiments have shown significant reductions in infarct size following ischemia and reperfusion.

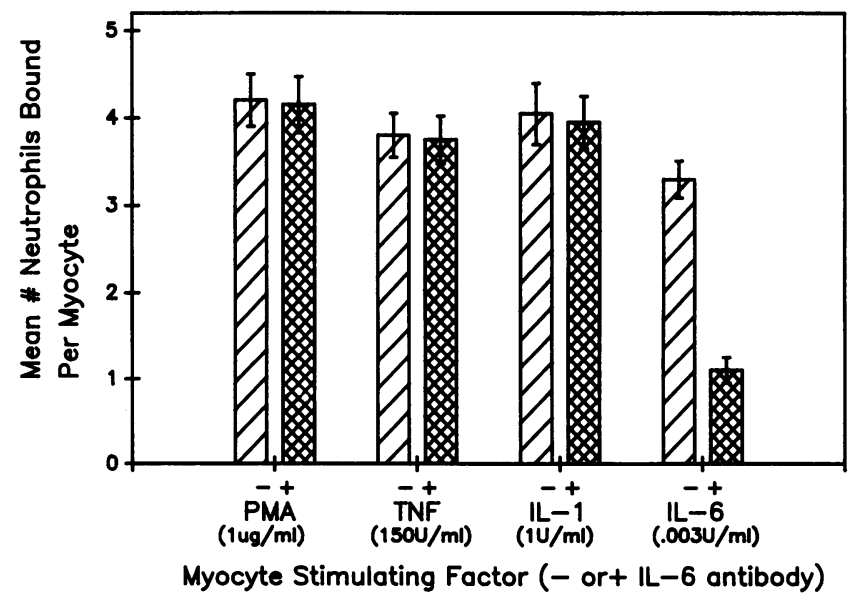

Figure 8. Specificity of anti-IL-6 antibodies. Isolated cardiac myocytes were incubated at $37^{\circ} \mathrm{C}$ for $3 \mathrm{~h}$ with PMA, rTNF $\alpha$, rIL- $1 \beta$, or rIL- 6 at concentrations which induced maximum adhesiveness for canine neutrophils both with $(\square)$ and without $(\varpi)$ anti-IL-6 antibodies $(0.004 \mathrm{U} / \mathrm{ml})$. Neutrophils and ZAS (1\%) were added during the fourth hour and adhesion was determined visually. 


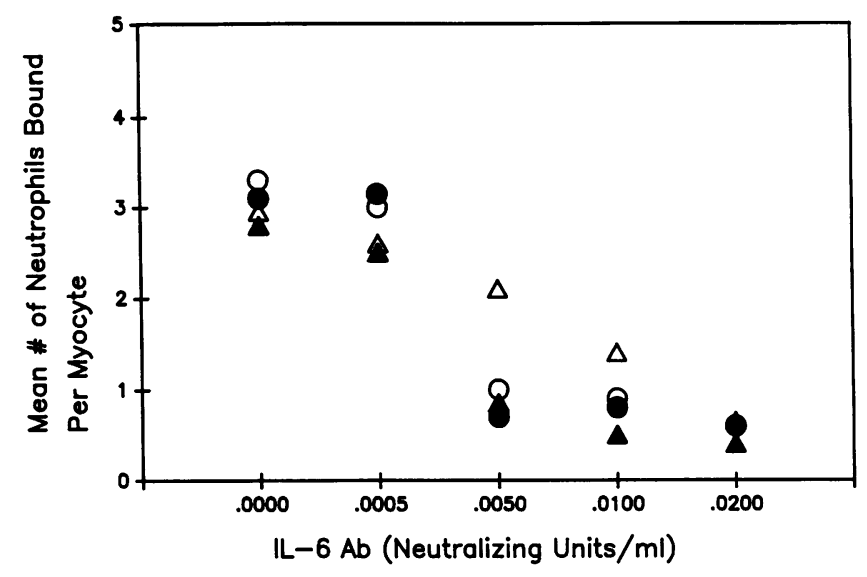

Figure 9. The effect of IL-6 neutralizing antibody on neutrophilmyocyte adherence induced by postischemic cardiac lymph. Dilutions (1:7) of the 90-min reperfusion sample of cardiac lymph from four experimental animals (each indicated by a different symbol) were incubated with rIL-6 neutralizing antibody at the concentrations indicated and isolated canine cardiac myocytes for $3-\mathrm{h}$ at $37^{\circ} \mathrm{C}$. During the fourth hour neutrophils and ZAS (1\%) were added, and adhesion was determined visually.

Recent evidence indicates that even short periods of ischemia ranging from 15 to 90 min may induce inflammatory damage (42).

While many studies indicate a role for inflammation in myocardial damage following ischemia, the mechanisms of induction of this inflammation are not well understood. The work of Hill and Ward (43) and Pinckard and co-workers (44)

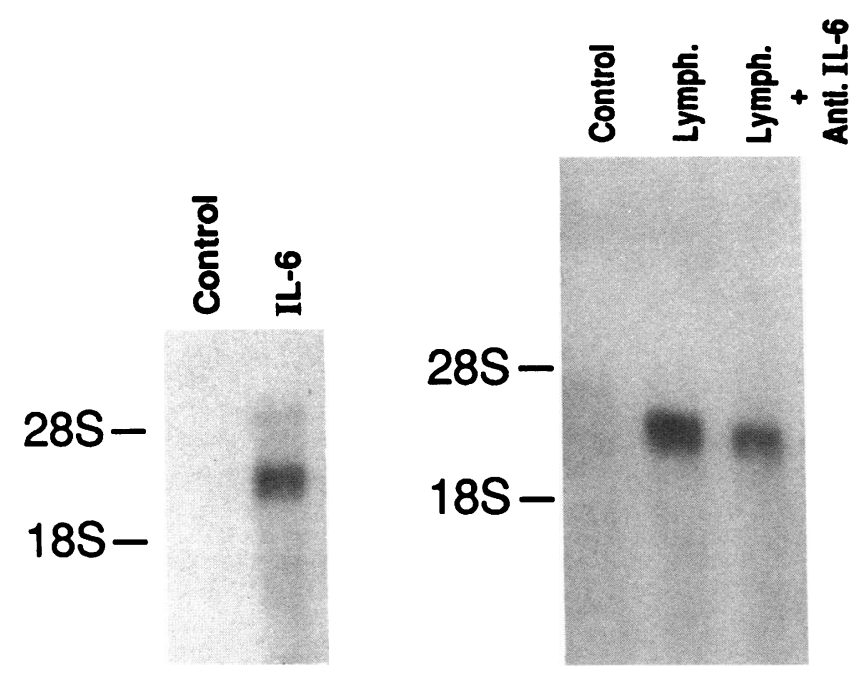

Figure 10. Effect of rIL-6 or postischemic cardiac lymph on canine ICAM-1 mRNA in cardiac myocytes. Isolated myocytes were preincubated with human rIL-6 $(0.01 \mathrm{U} / \mathrm{ml})$ or postischemic cardiac lymph (1:2 dilution in PBS) for $3 \mathrm{~h}$ at $37^{\circ} \mathrm{C}$ after which total cell RNA was isolated as described in methods. Northern blots of myocyte RNA $(20 \mu \mathrm{g})$ were probed with ${ }^{32} \mathrm{P}$-labeled canine ICAM-1 cDNA. As shown, a single 3.0-kb hybridizing band is present in both rIL-6 (left) and postischemic lymph (right) stimulated preparations; ICAM-1 mRNA is not evident in myocytes incubated in PBS (left) or in preischemic cardiac lymph (right, control), and relatively diminished levels of ICAM-1 mRNA are observed when myocytes are incubated in post-ischemic lymph with anti-IL-6 antibody ( 0.1 neutralizing $\mathrm{U} / \mathrm{ml})$.

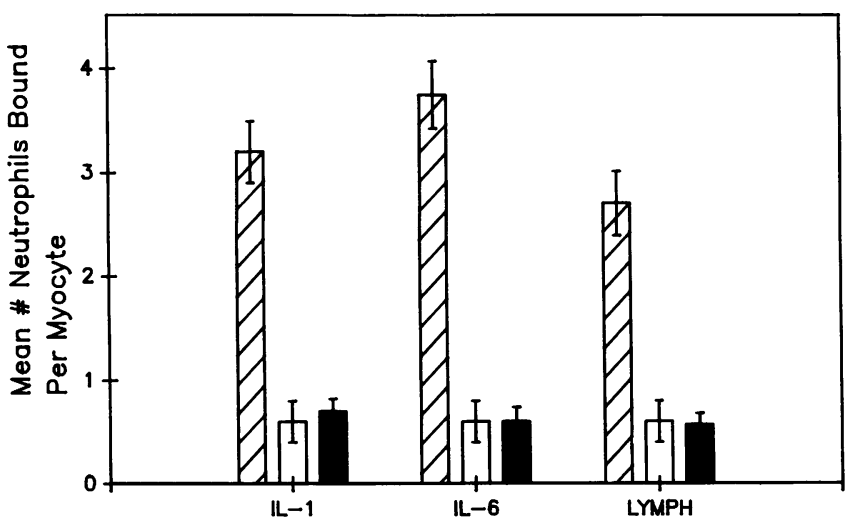

Figure 11. The dependence of neutrophil-myocyte adherence on ICAM-1. Isolated myocytes were incubated with $\mathrm{rIL}-1 \beta(2 \mathrm{U} / \mathrm{ml})$, rIL-6 $(0.01 \mathrm{U} / \mathrm{ml})$, or postischemic cardiac lymph $(1: 7)$ for $3 \mathrm{~h}$ at $37^{\circ} \mathrm{C}$, and then mixed with neutrophils and ZAS (10\%) for an additional hour at $37^{\circ} \mathrm{C}$. Adherence was determined visually and results are indicated by the hatched bars. The effects of anti-ICAM- 1 MAb CL18/6 $(10 \mu \mathrm{g} / \mathrm{ml})$ are shown in the open bars, and the effects of anti-CD18 MAb R15.7 (20 $\mu \mathrm{g} / \mathrm{ml})$ are shown in the solid bars.

suggested that complement-derived factors might be important in the inflammatory reaction. We have demonstrated a co-localization of $\mathrm{Clq}$ and neutrophils in ischemic myocardial segments after periods of ischemia as short as $45 \mathrm{~min}(42)$, and the appearance in cardiac lymph during reperfusion of $\mathrm{Clq}$ binding proteins capable of activating the classical complement pathway $(13,14)$. In addition, postischemic cardiac lymph is capable of inducing shape change, increased surface expression of $\mathrm{CD} 1 \mathrm{lb} / \mathrm{CD} 18$, increased intercellular adherence, and chemotaxis of exogenous neutrophils (15). Neutrophils found within the cardiac lymph have also been shown to express increased surface levels of CD11b/CD18 (15). These data are consistent with the hypothesis that macromolecules of myocardial origin that appear in postischemic cardiac lymph and initiate the classical complement pathway are responsible for the neutrophil stimulating activity demonstrated in the cardiac lymph $(13,14)$. In fact, Dreyer et al. (45) have recently shown that anti-C5a antibodies will inhibit most of this stimulatory activity.

The results in the present report demonstrate that postischemic cardiac lymph can also stimulate the cardiac myocytes in vitro to become adhesive for neutrophils, thus indicating that the extracellular fluid in the ischemic and reperfused myocardium contains the factors needed to activate not only the adhesive mechanisms of neutrophils as indicated above, but those of cardiac myocytes. Thus, the conditions needed for neutrophil adhesion to myocytes may also exist in the reperfused tissue. The pathogenic consequences of such adhesion are not yet known, but several observations in vitro and in vivo suggest that it may promote neutrophil-mediated damage to the myocyte. From studies in vitro there is evidence that adhesion to myocytes greatly augments hydrogen peroxide production by chemotactically stimulated neutrophils (9), and studies in vivo demonstrate that anti-CD11b MAb 904 reduces the area of infarction in a canine model of ischemia and reperfusion (40, 41). This MAb is particularly active in inhibiting the adherence-dependent production of hydrogen peroxide by canine neutrophils (12). One of the most commonly invoked mecha- 
nisms of inflammatory damage directly to a myocardial cell involves the production of oxygen free radicals by the neutrophils inducing cell injury (46). In order for such a direct mechanism to occur, it would be necessary for a neutrophil to adhere to or very closely approach a cardiac myocyte. The short halflife and high reactivity of these radicals virtually preclude diffusion across a significant distance in extracellular fluid.

We hypothesize that myocardial ischemia must involve a mechanism by which cytokines stimulate the adherence properties of endothelial cells and cardiac myocytes, a complex and dynamic process which presumably promotes transendothelial migration by neutrophils and elicits their cytotoxic activities in extravascular tissues. Our experimental approach has exploited the opportunity to use cardiac lymph as a monitor of extracellular macromolecules within the myocardium and to assess the capacity of postischemic cardiac lymph to induce ICAM-1 in these cell types. Our results clearly indicate the early appearance in ischemic lymph of IL-6 and probably other cytokines. A brief ( $30 \mathrm{~min}$ ) exposure of cardiac myocytes to these cytokines has prolonged effects on the cell's adhesiveness for neutrophils, and these cytokines persist in cardiac lymph for up to 72 $\mathrm{h}$ after the initial ischemic event. In contrast to the characteristics of chemotactic factors demonstrated in cardiac lymph collected under identical experimental conditions (15), the present studies show that cytokine activity is demonstrable in higher dilutions of cardiac lymph and that it persists for much longer time intervals.

Studies described in the current manuscript suggest that induction of ICAM-1 on cardiac myocytes is mediated primarily by IL-6. However, the stimulation of endothelial ICAM-1 by postischemic cardiac lymph does not appear to involve IL-6 since rIL-6 does not directly stimulate these cells, and anti-IL6 did not inhibit the effects of postischemic lymph. Thus, other cytokines may be important in the induction of inflammation in situ. ICAM-1 is constitutively expressed on endothelial cells $(47,48)$ but not on cardiac myocytes. Thus, the importance and extent of up-regulation of endothelial ICAM-1 in response to ischemic injury is not known, and the levels of endothelial ICAM-1 required for neutrophil adhesion and sequestration in vivo may be relatively low. In our current study, the induction of ICAM-1 by cardiac lymph on CJVEC was relatively weak compared to that for myocytes, and the stimulatory activity was detected for a shorter time after reperfusion was begun.

An important role for IL-6 has been previously implicated in a variety of other cellular responses such as the mediation of the acute phase reaction in hepatocytes $(49,50)$ and the modulation of immunologic responses dependent on lymphocytes (51) functions. This report represents the first demonstration that IL-6 may induce intercellular adherence molecules on mesenchymal cells and thereby influence neutrophil functions. IL6 is secreted by endothelial cells and by activated monocytes or phagocytes (52) which are potential sources of the IL-6 found in the cardiac lymph. A unifying hypothesis might suggest that complement activation of monocytes and tissue macrophages elicits their secretion of IL-6 which, in turn, induces myocyte ICAM-1. Coupled with our recent studies suggesting an obligate role for ICAM-1 in neutrophil-mediated myocyte injury (53), one might speculate that IL-6 induced ICAM-1 expression makes the myocardium vulnerable to inflammatory injury for a considerable time after reperfusion has occurred. Although future studies will investigate these possible mechanisms, it is interesting to note that the earliest laboratory tests utilized to clinically evaluate acute myocardial infarction assessed products of the acute hepatic phase reaction (sedimentation rate, $\mathrm{C}$-reactive protein) that are now known to be induced by IL-6 (49).

\section{Acknowledgments}

The expert technical assistance of Peggy Jackson, Gary Liedtke, Caryl Lane, Sharon Krater, and B. J. Hughes is acknowledged, as well as the expert secretarial assistance of Irene A. Harrison, C. Mata, and Michelle Swarthout.

This work was supported in part by National Institute of Health grants HL-42550, HL-23161, HL-41408, AI-19031, GM-23531, and AI-28071, Boehringer-Ingelheim Pharmaceuticals, Inc., and the David Wolff Foundation.

\section{References}

1. Mullane, K. M., and C. W. Smith. 1990. The role of leukocytes in ischemic damage, reperfusion injury and repair of the myocardium. In Pathophysiology of Severe Ischemic Myocardial Injury. H. M. Piper, editor. Kluwer Academic Publishers, Dordrecht. 239-267.

2. Romson, J. L., B. G. Hook, S. L. Kunkel, G. D. Abrams, M. A. Schork, and B. R. Lucchesi. 1983. Reduction of the extent of ischemic myocardial injury by neutrophil depletion in the dog. Circulation. 67:1016-1023.

3. Jolly, S. R., W. J. Kane, B. G. Hook, G. D. Abrams, S. L. Kunkel, and B. R. Lucchesi. 1986. Reduction of myocardial infarct size by neutrophil depletion: effect of duration of occlusion. Am. Heart J. 112:682-690.

4. DeLorgeil, M., A. Basmadjian, M. Lavalle, R. Clement, D. Millette, G. Rousseau, and J. G. Latour. 1989. Influence of leukopenia on collateral flow, reperfusion flow, reflow ventricular fibrillation, and infarct size in dogs. Am. Heart J. 117:523-532.

5. Engler, R. L., G. W. Schmid-Schonbein, and R. S. Parelec. 1983. Leukocyte capillary plugging in myocardial ischemia and reperfusion in the dog. Am. J. Pathol. 111:98-111.

6. Schmid-Schoenbein, G. W., and R. L. Engler. 1987. Granulocytes as active participants in acute myocardial ischemia and infarction. Am. J. Cardiovasc. Pathol. 1:15-30.

7. Worthen, G. S., B. Schwab III, E. L. Elson, and G. P. Downey. 1989 Mechanics of stimulated neutrophils: Cell stiffening induces retention in capillaries. Science (Wash. DC). 245:183-186.

8. Mullane, K. M., W. Westlin, and R. Kraemer. 1988. Activated neutrophils release mediators that may contribute to myocardial dysfunction associated with ischemia and reperfusion. In Biology of the Leukotrienes. New York Academy of Science, New York. 103-121.

9. Entman, M. L., K. Youker, S. B. Shappell, C. Siegel, R. Rothlein, W. J. Dreyer, F. C. Schmalstieg, and C. W. Smith. 1990. Neutrophil adherence to isolated adult canine myocytes: evidence for a CD18-dependent mechanism. $J$. Clin. Invest. 85:1497-1506.

10. Smith, C. W., M. L. Entman, C. L. Lane, A. L. Beaudet, T. I. Ty, K. Youker, H. K. Hawkins, and D. C. Anderson. 1991. Adherence of neutrophils to canine cardiac myocytes in vitro is dependent on intercellular adhesion molecule1. J. Clin. Invest. 88:1216-1223.

11. Nathan, C. F. 1987. Neutrophil activation on biological surfaces: massive secretion of hydrogen peroxide in response to products of macrophages and lymphocytes. J. Clin. Invest. 80:1550-1560.

12. Shappell, S. B., C. Toman, D. C. Anderson, A. A. Taylor, M. L. Entman, and C. W. Smith. 1990. Mac-1 (CD1 1b/CD18) mediates adherence-dependent hydrogen peroxide production by human and canine neutrophils. J. Immunol. 144:2702-2711.

13. Rossen, R. D., L. H. Michael, A. Kagiyama, H. E. Savage, G. Hanson, J. N. Reisbery, J. N. Moake, S. H. Kim, S. Weakly, E. Giannini, and M. L. Entman. 1988. Mechanism of complement activation following coronary artery occlusion: evidence that myocardial ischemia causes release of constituents of myocardial subcellular origin which complex with the first component of complement. Circ. Res. 62:572-584.

14. Kagiyama, A., H. E. Savage, L. H. Michael, G. Hanson, M. L. Entman, and R. D. Rossen. 1989. Molecular basis of complement activation in ischemic myocardium: identification of specific molecules of mitochondrial origin that bind Clq and fix complement. Circ. Res. 64:604-615.

15. Dreyer, W. J., C. W. Smith, L. H. Michael, R. D. Rossen, B. J. Hughes, M. L. Entman, and D. C. Anderson. 1989. Canine neutrophil activation by cardiac lymph obtained during reperfusion of ischemic myocardium. Circ. Res. 65:1751-1762.

16. Smith, C. W., S. D. Marlin, R. Rothlein, C. Toman, and D. C. Anderson. 1989. Cooperative interactions of LFA-1 and Mac-1 with intercellular adhesion 
molecule-1 in facilitating adherence and transendothelial migration of human neutrophils in vitro. J. Clin. Invest. 83:2008-2017.

17. Miller, L. J., D. F. Bainton, N. Borregaard, and T. A. Springer. 1987. Stimulated mobilization of monocyte Mac-1 and p150,95 adhesion proteins from an intracellular vesicular compartment to the cell surface. J. Clin. Invest. 80:535-544.

18. Smith, C. W., R. Rothlein, B. J. Hughes, M. M. Mariscalco, F. C. Schmalstieg, and D. C. Anderson. 1988. Recognition of an endothelial determinant for CD18-dependent human neutrophil adherence and transendothelial migration. J. Clin. Invest. 82:1746-1756.

19. Smith, C. W., J. C. Hollers, R. A. Patrick, and C. Hassett. 1979. Motility and adhesiveness in human neutrophils: Effects of chemotactic factors. J. Clin. Invest. 63:221-229.

20. Saiki, R. K., D. H. Gelfand, S. Stoffel, S. J. Scharf, R. Higuchi, G. T. Horn, K. B. Mullis, and H. A. Erlich. 1988. Primer-directed enzymatic amplification of DNA with a thermostable DNA polymerase. Science (Wash. DC). 239:487-491.

21. Maniatis, T., E. F. Fritsch, and J. Sambrook. 1989. Molecular Cloning: A Laboratory Manual. Cold Spring Harbor Laboratory, Cold Spring Harbor, New York.

22. Feinberg, A. P., and B. Vogelstein. 1983. A technique for radiolabeling DNA restriction endonuclease fragments to high specific activity. Anal. Biochem. 132:6-13.

23. Yanisck-Perron, C., J. Vieira, and J. Messing. 1985. Improved M13 phage cloning vectors and host stains: Nucleotide sequences of the M13 M118 and pUC19 vectors. Gene. 33:103-119.

24. Sanger, F., S. Nicklen, and A. R. Coulson. 1977. DNA sequencing with chain terminating inhibitors. Proc. Natl. Acad. Sci. USA. 74:5463-5468.

25. Chomczynski, P., and N. Sacchi. 1987. Single-step method of RNA isolation by acid guanidinium thiocyanate-phenol-chloroform extraction. Anal. Biochem. 162:156-159.

26. Hannum, C. H., C. J. Wilcox, W. P. Arend, F. G. Joslin, D. J. Dripps, P. L. Heimdal, L. G. Armes, A. Sommer, S. P. Eisenberg, and R. C. Thompson. 1990 Interleukin-1 receptor antagonist activity of a human interleukin-1 inhibitor. Nature (Lond.). 343:336-340.

27. Eisenberg, S. P., R. J. Evans, W. P. Arend, E. Verderber, M. T. Brewer, C. H. Hannum, and R. C. Thompson. 1990. Primary structure and functional expression from complementary DNA of a human interleukin-1 receptor antagonist. Nature (Lond.). 343:341-346.

28. Carter, D. B., M. R. Deibel, C. J. Dunn, C. S. Tomich, A. L. Laborde, J. L. Slightom, A. E. Berger, M. J. Bienkowski, et al. 1990. Purification, cloning, expression and biological characterization of an interleukin-1 receptor antagonist protein. Nature (Lond.). 344:633-637.

29. Diamond, M. S., D. E. Staunton, A. R. deFougerolles, S. A. Stacker, J. Garcia-Aguilar, M. L. Hibbs, and T. A. Springer. 1990. ICAM-1 (CD54): a counter-receptor for Mac-1 (CD11b/CD18). J. Cell Biol. 111:3129-3139.

30. Engler, R. L., M. D. Dahlgren, M. A. Peterson, A. Dobbs, and G. W. Schmid-Schonbein. 1986. Accumulation of polymorphonuclear leukocytes during 3h experimental myocardial ischemia. Am. J. Physiol. 251:H93-100.

31. Smith, E. F., J. W. Egan, P. J. Bugelshi, L. M. Hillegass, and D. E. Hill. 1988. Temporal relation between neutrophil accumulation and myocardial reperfusion. Am. J. Physiol. 255:H1060-H1068.

32. Mullane, K. M., R. Kraemer, and B. Smith. 1985. Myeloperoxidase activity as a quantitative assessment of neutrophil infarction of myocardium. J. Pharmacol. Exp. Ther. 14:157-167.

33. Mehta, J. L., W. W. Nichols, and P. Mehta. 1988. Neutrophils as potential participants in acute myocardial ischemia: relevance to reperfusion. J. Am. Coll. Cardiol. 11:1309-1316.

34. Mullane, K. M., N. Read, J. A. Salmon, and S. Moncada. 1984. Role of leukocytes in acute myocardial infarction in anesthetized dogs: relationship to myocardial salvage by anti-inflammatory drugs. J. Pharmacol. Exp. Ther. 228:510-522.

35. Lucchesi, B. R., J. L. Romson, and S. R. Jolly. 1984. Do leukocytes influence infarct size? In Therapeutic Approaches to Myocardial Infarct Size Limitation. D. J. Hearse, and D. M. Mellon, editors. Raven Press, New York 219-248.
36. Engler, R. L., M. D. Dahlgren, D. D. Morris, M. A. Peterson, and G. W. Schmid-Schonbein. 1986. Role of leukocytes in response to acute myocardial ischemia and reflow in dogs. Am. J. Physiol. 251:H314-323.

37. Simpson, P. J., J. Mickelson, J. C. Fantone, K. P. Gallagher, and B. R. Lucchesi. 1987. Iloprost inhibits neutrophil function in vitro and in vivo and limits experimental infarct size in canine heart. Circ. Res. 60:666-673.

38. Romson, J. L., B. G. Hook, V. H. Rigot, M. A. Schork, D. P. Swanson, and B. R. Lucchesi. 1982. The effect of ibuprofen on accumulation of "IIIndium labeled platelets and leukocytes in experimental myocardial infarction. Circulation. 66:1002-1011.

39. Mullane, K. M. 1988. Myocardial ischemia-reperfusion injury: role of neutrophils and neutrophil derived mediators. In Human Inflammatory Disease. Clinical Immunology. G. Marone, L. M. Lichtenstein, M. Condorell, and A. S. Fauci, editors. B. C. Decker Inc., Philadelphia, PA. 143-159.

40. Simpson, P. J., III, R. F. Todd, J. C. Fantone, J. K. Mickelson, J. D. Griffin, and B. R. Lucchesi. 1988. Reduction of experimental canine myocardial reperfusion injury by a monoclonal antibody (anti-Mol, anti-CD11b) that inhibits leukocyte adhesion. J. Clin. Invest. 81:624-629.

41. Simpson, P. J., III, R. F. Todd, J. K. Mickelson, J. C. Fantone, K. P. Gallagher, K. A. Lee, Y. Tamura, M. Cronin, and B. R. Lucchesi. 1990. Sustained limitation of myocardial reperfusion injury by a monoclonal antibody that alter leukocyte function. Circulation. 81:226-237.

42. Rossen, R. D., J. L. Swain, L. H. Michael, S. Weakley, E. Giannini, and M. L. Entman. 1985. Selective accumulation of the first component of complement and leukocytes in ischemic canine heart muscle: a possible initiator of an extra myocardial mechanism of ischemic injury. Circ. Res. 57:119-130.

43. Hill, J. H., and P. A. Ward. 1971. The phlogistic role of C3 leukotactic fragment in myocardial infarcts of rats. J. Exp. Med. 133:885-900.

44. Pinckard, R. N., M. S. Olson, R. E. Kelley, D. H. Detter, J. D. Palmer, R. A. O'Rourke, and S. Goldfein. 1973. Antibody-independent activation of human $\mathrm{Cl}$ after interaction with heart subcellular membranes. J. Immunol. 110:1376-1382.

45. Dreyer, W. J., L. H. Michael, R. D. Rossen, T. Nguyen, D. C. Anderson, C. W. Smith, and M. L. Entman. 1991. Evidence for C5a in post-ischemic canine cardiac lymph. Clin. Res. 39:271A. (Abstr.)

46. Lucchesi, B. R., and K. M. Mullane. 1986. Leukocytes and ischemia induced myocardial injury. Annu. Rev. Pharmacol. Toxicol. 26:201-224.

47. Dustin, M. L., R. Rothlein, A. K. Bhan, C. A. Dinarello, and T. A. Springer. 1986. Induction by IL-1 and interferon-gamma: tissue distribution biochemistry, and function of a natural adherence molecule (ICAM-1). J. Immunol. 137:245-254.

48. Munro, J. M., J. S. Pober, and R. S. Cotran. 1989. Tumor necrosis factor and interferon-gamma induce distinct patterns of endothelial activation and associated leukocyte accumulation in skin of papio anubis. Am. J. Pathol. 135:121133.

49. Rokita, H., M. Mackiewicz, and A. Koj. 1989. Acute phase response to recombinant interleukin-6 and macrophage- and fibroblast-derived crude cytokine preparations in primary cultures of mouse hepatocytes. Cell Biochem. Func. 7:257-262.

50. Lombardo, A., L. Caimi, S. Marchesini, G. Gai, and G. Tehamanti. 1980. Enzymes of lysosomal origin in human plasma and serum:assay conditions and parameter influencing the assay. Clin. Chem. Acta. 108:337-346.

51. Sehgal, P. B., D. C. Helfgott, U. Santhanam, S. B. Tatter, R. H. Clarick, J. Ghrayeb, and L. T. May. 1988. Regulation of the acute phase and immune responses in viral disease. J. Exp. Med. 167:1951-1956.

52. Fong, Y., L. L. Moldawer, M. A. Marano, H. Wei, S. B. Tatter, R. H Clarick, U. Santhanam, D. Sherris, L. T. May, P. B. Sehgal, et al. 1989. Endotoxemia elicits increased circulating beta2-IFN/IL-6 in man. J. Immunol. 142:23212324.

53. Entman, M. L., K. Youker, T. Shoji, A. A. Taylor, S. B. Shappell, and C. W. Smith. 1991. Neutrophil-induced oxidative injury of cardiac myocytes is a compartmented system requiring CD11/CD18-ICAM-1 adherence. Clin. Res. 39:159A. (Abstr.) 